\title{
Pupils' meta-discursive reflection on their cooperation in mathematics: a case study
}

\author{
Petros Chaviaris, Sonia Kafoussi and Francois Kalavassis
}

\begin{abstract}
This article addresses the issue of how 10-11 year old pupils in pairs can actively get involved in reforming their behavior as they reflect on their interaction in order to solve mathematical problems. We studied the opportunities offered for the development of meta-discursive reflection in a pair of pupils in two alternative environments: (1) pupils' observations and discussions on their video-recorded cooperation and (2) pupils' participation in playing and acting in a drama. The results of the research revealed three levels of the pupils' meta-discursive reflection on their interaction: (1) focusing on the achievement of personal goals, (2) focusing on partners' responsibility and (3) focusing on mutual responsibility. Both environments helped the pupils to improve their socio-mathematical interaction.
\end{abstract}

Key words and phrases: elementary school, drama, meta-discursive reflection, observation of video-recorded cooperation, small-group interaction.

ZDM Subject Classification: A70, B10, C60.

\section{Introduction}

The investigation on issues concerning social interaction that takes place in a class community continues to be of great interest among mathematics educators. Van Oers has pointed out that a basic orientation in mathematics education nowadays is the study of the relationship between the social interaction of pupils and the development of common mathematical meanings in the classroom [1]. 
This is a consequence of the acceptance of the following point of view: If educators are to comprehend pupils' learning in mathematics, classroom life has to be interpreted not only from a psychological perspective but from a sociological perspective as well [2], [3]. In this concept, research has been mainly focused on the teacher's role of initiating and guiding the establishment of new rules of sociomathematical interaction among pupils [4], [5], [6]. On the other hand, there is a lot of interest about the ways that pupils can become aware of the learning processes in specific domains (cf. [7]). However, little research has been done on pupils' reflection in order to improve their socio-mathematical interaction in the class as well as on the dynamic of environments that could give opportunities for pupils' own engagement towards this effort [8].

This article provides focus on how pupils in pairs can actively get involved in reforming their behavior as they reflect on their interaction in order to solve mathematical problems. More specifically, we investigated the opportunities given to 10-11 year old pupils to reflect on their socio-mathematical interaction in order to improve it in two alternative environments: (1) observation and discussion of pupils in pairs on their video-recorded cooperation and (2) pupils' participation in playing and acting in a drama. In this article, we will present a case study concerning the work of a pair (Apostolos and Elsa), as the pupils of this pair had negative beliefs about cooperation in mathematics and they experienced difficulties in this school subject.

\section{Theoretical framework}

Many researchers have developed theoretical constructs for the study of the relation between the pupil's cognitive development and social interaction in the classroom. For example, interpretative constructs for this purpose are didactical contract [9], social and socio-mathematical norms [10], thematic patterns of interaction [11] or meta-discursive rules [12]. Although these researchers have started from different theoretical viewpoints (e.g. constructivism, ethno-methodology, communicational approach) to develop their constructs, their work converges on the acceptance of the significance of pupils' beliefs and intentions for the development of their interaction during their mathematical activity.

Yackel and Cobb have pointed out that the development of norms in a mathematics class and pupils' beliefs are complementary [10]. Their emergent perspective connects social norms with general beliefs, socio-mathematical norms 
"chaviaris" — 2007/8/10 — 11:57 — page $149-\# 3$

with mathematical beliefs and values, and classroom mathematical practices with mathematical conceptions [13].

Similarly, one basic hypothesis of the interactionist approach is that a participant of an interaction in the mathematics classroom "monitors his or her action in accordance with what he assumes to be the other participants background, understandings, expectations ... At the same time the other participants make sense of the action by adopting what they believe to be the actor's background, understandings, intentions." [11, p. 169]. As a consequence, every member of a mathematics class tacitly participates in his/her own way in interacting with others according to his/her personality (interests, expectations, intentions, beliefs).

Sfard has mentioned that pupils' initiation to mathematical discourse depends on the "meta-discursive rules that regulate the communicative effort" [12, p. 28]. These rules are considered as the implicit regulators of interpersonal and intrapersonal communication, as they determine the choices of the participants when they act and they embed their values and beliefs. She has emphasized the role of the interlocutors' intentions in a mathematical discussion using the term "metadiscursive intentions" in order to describe the "interlocutors' concerns about the way the interaction is being managed and the issues of the relationship between interlocutors" (p. 39).

As a consequence, we would agree with Moschkovich, that mathematical discussion includes socio-mathematical actions of the participants, as "it incorporates ways of thinking, acting, reading, writing as well as values, beliefs and points of view" [14, p. 326]. Although a lot of research has focused on metacognition for the study of the way that pupils can become aware of their own thinking and actions during their mathematical activity, Zimmerman has stressed that the interpretation of pupils' self-regulation has to be treated as a complex interactive process influenced by pupils' self beliefs-system [15]. Therefore, metacognition could also be studied as a meta-discursive process that is pupils' reflection on their own and their interlocutors' beliefs and intentions about their interaction. Towards this effort, the study of the development of pupils' meta-discursive reflection could allow a deeper understanding of the improvement of socio-mathematical interaction among them.

In mathematics education, many researches investigating social interaction in classroom have been focused on cooperative learning contexts concerning small groups of pupils. These researches have revealed a lot of factors that influence pupils' mathematical learning. Group composition, pupils' beliefs about their cooperation in mathematics, pupils' achievement in mathematics, the quality of 
mathematical activities, the stabilization of concrete behavior by the participants (e.g. the pupil who helps and the pupil whom is helped) have been mentioned by many researchers [16], [17], [18], [19]. Furthermore, the research on meta-cognition in mathematical learning has indicated the positive effects of cooperative metacognitive instruction on pupils' achievement [20], [21], [22], [23], [24]. A fruitful environment for the development of meta-cognitive processes is pupils' classroom discussion on mathematics. This can be seen by observation and evaluation of such videotaped sessions [25], [26]. However, these researches have usually taken place in secondary education and have focused on cognitive analyses of the pupils' mathematical discussions.

As to the role of playing and acting in a drama on learning and teaching of mathematics, little research has been done [27]. There are no studies about the role of drama as an environment for pupils' meta-discursive reflection on their socio-mathematical interaction. However, Andersen has stressed that "learnersin-role benefit not only from engaging with realistic problems, but also by working and thinking within realistic roles. ... First, the learner-in-role adopts the thinking of that role ... Second, simultaneous thinking as, the learner is thinking about the role, monitoring one's own thinking and action" [28, p. 1]. Role-playing allows both individual and collective reflection on an experience. An experience about one's own self is not productive or non-productive, but it can be significant through someone's reflection on it [29].

The present study focuses on the following questions:

(1) How do pupils in pairs develop their meta-discursive reflection on their sociomathematical interaction as observed and discussed on their videotaped cooperation?

(2) Which opportunities can the pupils' playing and acting in a drama offer for reflection on their interaction in mathematics?

\section{Method}

The designing and the realization of the research program was based on patchwork case studies method [30] as well as on components of critical action research $[31]^{1}$.

\footnotetext{
${ }^{1}$ According to Kemmis (1993) the method of action research "is always connected to social action... It is trying to understand and improve the ways things are in relation to how they could be better ... it aims at creating a form a collaborative learning by doing (in which groups
} 
The research program took place in a fifth grade of a typical public school of Athens, Greece in 2003-2004 and it lasted six months. The participants were 18 pupils ( 9 boys and 9 girls) that worked in pairs, 4 times per week during math class teaching. The teacher of the class voluntarily accepted the development of this research program in her classroom. The mathematical topic in which the pupils were engaged during the research program concerned the concept of fractions.

\section{Data collection and analysis}

The research program was developed in three phases. Initially, we studied the pupils' profiles in order to organize them in pairs. All the pupils were interviewed about their beliefs of their own participation and the others' participation during the classroom mathematical activity as well as about the nature and the goals of mathematical activity. Every interview lasted about one hour. Moreover, we investigated the pupils' informal knowledge on fractions using a questionnaire with mathematical problems on this topic. Finally, the teacher of the class was asked to assess her pupils in mathematics based on her personal evaluation by using the criterion of the pupil's need for help in order to solve a mathematical problem (He/She does not need help - He/She needs some help - He/She needs a lot of help) as well as provide the pupils' grades in mathematics of the previous school year. According to the above data, we organized nine pairs of pupils, based on the following criteria: (1) the pupils' positive or negative beliefs about cooperation in mathematics, (2) the pupils' informal knowledge on fractions, (3) the teacher's assessment of her pupils and (4) the pupils' wish to cooperate with one of their classmates.

In the second phase of the program, the mathematical activities were designed according to the related literature [32] and the pupils' initial knowledge of fractions [33], [34], [35]. However, we should note that the activities were reconstructed according to the pupils' mathematical development during the program. The pupils' cooperation was videotaped once a week for every pair in the class by the researcher and then the members of the group participated in a session with him. During this session, the pupils observed and discussed issues concerning their video-recorded cooperation. These discussions were tape-recorded. Moreover, the pupils of each pair were asked to play and act in a drama in the classroom based on the experiences of their cooperation. This activity was developed in three

of participants set out to learn from change in a process of making changes, studying the process and consequences of these changes and trying again)" (p. 4-5). 
"chaviaris" $-2007 / 8 / 10-11: 57-$ page $152-\# 6$

phases: (1) designing their role in a drama, (2) presenting their drama to the class and (3) discussing their roles with their classmates. All the phases of this activity were videotaped.

In the third phase, the members of each pair were interviewed again about their beliefs of their own and the others' participation in mathematics as well as the nature and the goals of mathematical activity.

Thus, the data consisted of the videotaped recordings of the pairs' work in mathematics, the recordings of the pupils' discussions about their own videotaped cooperation, the videotaped recordings of the pupils' drama and the transcripts of the tape-recorded clinical interviews conducted with each pupil at the beginning and at the end of the program. All these data were composed together to a diary for every pair.

The analysis of the data was realized in three levels: the discursive, the metadiscursive and the collective one. In the first level, discourse analysis of the pairs' engagement in classroom mathematical activities was based on the interactivity flowcharts that Sfard and Kieran have developed [36] (cf. appendix). More specifically, we used interactivity analysis in order to specify the development of interaction of every pair in relation to the change of the intentions of each member. In the meta-discursive level, the tape-recorded pupils' discussions about their own videotaped cooperation were analyzed according to: (1) the way that the pupils assessed their cooperation (self-assessment), (2) the critical moments of their interaction and (3) the targets they set for their next cooperation (self-regulation). Moreover, in this level, their drama texts were analyzed according to the roles that the pupils chose to play as well as the relation between the scenarios that the pupils had created and their experiences from their cooperation in mathematics. Finally, in the collective level, we analyzed the pupils' comments as they discussed their roles in drama in relation to the feelings that these experiences provoked to them. The method used for the analysis of the results in the second and third levels was an analytical descriptive narrative one. The choice of this method was considered to be the most appropriate one. This opportunity was supported, e.g., by the following statement from the literature: "Analytic narrative is the foundation of an effective report of fieldwork research. The narrative vignette is a vivid portrayal of the conduct of an event of everyday life, in which the sights and sounds of what was being said and done are described in the natural sequence of their occurrence in real time" [37, p. 149-150]. 


\section{Results}

Initially, we will present the pupils' profile of this pair concerning their beliefs about cooperation in mathematics as well as the characteristics of their initial attempt to cooperate in the mathematics class. Then, we will focus on the evolution of the pupils' meta-discursive reflection in the two different environments: observing video-recorded sessions and participating in a drama. Finally, we will present an episode of the pupils' interaction at the end of the program that illustrates the changes in their interaction.

Before the presentation of the pupils' profile, we should note that, according to the data from the initial interviews that were conducted in this class, 8 pupils answered that they wanted to cooperate with their classmates in mathematics, 4 pupils answered that they wanted to work alone, and 6 pupils answered that they wanted to cooperate only with their teacher. The pupils' beliefs about the development of their cooperation were influenced by their achievement in mathematics. The pupils that expressed the wish to cooperate with their classmates were usually average or low achievers, and the pupils that expressed the wish to work alone were usually high achievers (according to the criteria described in the chapter on our research method). Furthermore, the pupils' justifications about their preferences revealed the following beliefs that prevented the development of cooperation in mathematics:

(1) mathematical knowledge is acquired with personal effort (e.g. "if someone doesn't work on their own, they cannot understand mathematics"),

(2) different ideas in mathematics cause confusion and create difficulties in understanding (e.g. "everyone can express their opinions and they might quarrel about which one is right as they are unable to make head or tail of it"),

(3) classmates' errors in mathematics negatively influence pupil's thinking and prevent their learning (e.g. "my classmate may make an error so I will be confused") and

(4) the exposition of a pupil's thinking to his/her classmates does not protect his/her self-image.

The goals set by the pupils about their mathematical activity were connected with the results of their efforts (right or wrong answer to a problem). We must mention that the pupils had not worked in groups in mathematics in previous years and their teacher was following a traditional approach in this subject. 


$$
\text { "chaviaris" - 2007/8/10 - 11:57 — page } 154-\# 8
$$

The pupils' profile

At the beginning of the program, both pupils, Apostolos (A) and Elsa (E), expressed their desire to cooperate only with their teacher in mathematics. Elsa justified her view as follows: "I have to try alone and only the teacher can help me when I have difficulties". She declared that she didn't want to help her classmates in mathematics because: "If I do not know it right, I will say it to the other pupils in a wrong way". On the other hand, Apostolos justified his own view as follows: "I have the impression that my classmates will think that I do not do well in mathematics and I don't like this". Although, both pupils expressed negative beliefs about cooperation in mathematics, their intentions differed. Apostolos wanted to protect his self-image and Elsa had low self-confidence in mathematics. Moreover, these views were connected with the targets that the two pupils posed for their mathematical activity. Apostolos declared that he felt happy in mathematics when he could solve a problem that his classmates "don't manage it". In contrary Elsa said: "I feel happy when I answer correctly to my teachers questions". In relation to the pupils' abilities in mathematics, their teacher commented that both pupils very often needed help to complete a mathematical activity.

During their initial attempts to cooperate as a group, the pupils worked individually and didn't negotiate their ideas. Most of their utterances were addressed to themselves, revealing, in this way, a private discourse and very few utterances indicated a challenge for reaction on the part of their interlocutor. They usually presented their solutions without arguments or explanations about them. The following episode is representative of this situation.

Episode 1: The pupils had to share fairly a chocolate among 2, 3, 4, 5, 6 children and to answer the question: In which case will a child get more chocolate and why? During their cooperation the following dialogue took place:

Table 1

\begin{tabular}{|l|l|l|}
\hline \multicolumn{2}{|l|}{ utterances } & writings \\
\hline 1 & $\begin{array}{l}\text { A: Here, it will be divided into two parts and } \\
\text { each one will eat half of it. }\end{array}$ & \\
$2^{\mathrm{a}}$ & A: Here, it is $1 / 3$. & {$\left[2^{\mathrm{a}}\right]$ He wrote } \\
& & $1 / 2$ and $1 / 3$ \\
$2 \mathrm{~b}$ & Is it written in this way? & \\
\hline
\end{tabular}




$$
\text { "chaviaris" — 2007/8/10 — 11:57 — page } 155 \text { — \#9 }
$$

\begin{tabular}{|l|l|l|}
\hline 3 & E: I think so. & (after personal work) A: In which case will a \\
$4^{\mathrm{a}}$ & $\begin{array}{l}{[3-5] \text { They }} \\
\text { child get more chocolate and why? } \\
\text { ab }\end{array}$ & $\begin{array}{l}\text { In the first case, but why? } \\
\text { E: Wait! } \\
5\end{array}$ \\
6 & $\begin{array}{l}\text { (after personal work) } \\
\text { E: I wrote that the children will get more } \\
\text { chocolate when they are six. }\end{array}$ \\
7 & $\begin{array}{l}\text { A: Ok, we know it. } \\
\end{array}$ & \\
\hline
\end{tabular}

The two pupils hardly talked, as there were only three moments when one of them provoked the reaction of his classmate (ut. $2 \mathrm{~b}-3,4 \mathrm{~b}-5,6-7$, cf. interactivity flowchart 1, appendix). Their interaction was mostly based on Apostolos' intention for confirmation of his decisions during his own mathematical activity (ut. $2 \mathrm{~b}, 4 \mathrm{~b})$. These proactions did not provide the opportunity for discussion between the pupils, as Elsa's responses were of one word and they prevented a dialogue (ut. 3,5$)$.

The evolution of the pupils' meta-discursive reflection

The study of the ways that the pupils assessed their interactions in mathematics and set targets for their improvement as well as the investigation of the critical moments of their reflections through the observation of their video-recorded cooperation and through participating in drama revealed three levels of development concerning the pupils' meta-discursive reflection. These levels could be described as follows: a) focusing on the achievement of personal goals, b) focusing on partners' responsibility, c) focusing on mutual responsibility.

a) Focusing on the achievement of personal goals

At the first level, the assessment of their cooperation mainly concerned the quantitative characteristics of their interaction (how much time they talked to each other) and the result of their personal effort to solve the problem. The critical mo-ments of their meta-discursive reflection focused on their partner's actions, which every pupil considered obstacles for his/her personal mathematical activity. More-over, the pair's self-regulation was mostly connected with the increase of their inter-action time. The following quotations are from their discussions when 


$$
\text { "chaviaris" — 2007/8/10 — 11:57 — page } 156 \text { — \#10 }
$$

they observed their video-taped cooperation and they illustrate the pupils' metadiscursive reflection at this level.

Self-assessment: In the first two sessions of the researcher with Apostolos and Elsa, the pupils commented which of them talked more. Elsa's justification about her non-participation in the discussion concerned the non-necessity of cooperation in mathematics and it can be interpreted according to her view on the role of personal effort in mathematical learning ("We spoke to each other only three times, because one might not need the other's cooperation and may want to solve the problem alone").

Critical moments: Both pupils commented that, during their initial efforts to cooperate, every member worked individually and they sometimes checked their solutions with their partner. Elsa declared: "Firstly, each of us solved the problem alone and then we showed it to our partner" and Apostolos said: "We wrote the solution and then we looked at our partner's solution". The pupils considered as obstacle to their mathematical activity their partner's suggestion about the way they had to think and act.

A: Elsa sometimes told me «It is not like this» or «Do this». I do not like her telling me what to do. Sometimes I tell her an idea but she does not tell me hers.

E: I don't like getting ready answers, either.

Self-regulation: The targets set by the pair were directly connected with their self-assessment and the critical moments of their reflection.

A: I would like to talk more, to cooperate more.

E: I would like to talk more, but I do not want him to tell me what I have to write, we will find the solu-tion together. Apostolos and I will think simultaneously, we will present our ideas and we will write the correct one.

\section{b) Focusing on partners' responsibility}

At the second level, the pupils' meta-discursive reflection began to focus on the qualitative characteristics of their interaction. The pupils began to assess their co-operation positively, when each partner expressed his/her own idea and then they de-cided which one is correct. The critical moments of their reflection concerned the role of their existing beliefs of their partner's ability in mathematics and the absence of explanation for a mathematical decision. It is remarkable that during the pupils' dis-cussion of the above issues, they tried to shift the responsibility of the difficulties of their interaction to their partner. Concerning 


$$
\text { "chaviaris" — 2007/8/10 — 11:57 — page } 157 \text { — \#11 }
$$

the self-regulation, the targets, which the pupils set for the improvement of their cooperation, concerned concrete actions that were usually addressed to their interlocutor: Offering an idea and explanation of the proposed idea from their partner.

Self-assessment: The following episode took place during their third videotaped cooperation and the corresponding session with the researcher. The activity given to the pupils aimed at the construction of equivalent fractions through structured material, as the pupils had already engaged in activities with unstructured materials. The pupils did not manage to solve correctly this problem as they did not initially take into account all the elements of the problem (the number of children) and then they were confused about the unit of reference in every case.

Episode 2: On the tables in the picture pizzas have been served. Imagine that on the first table there are 2 children, on the second table 4 children and on the third table 8 children.
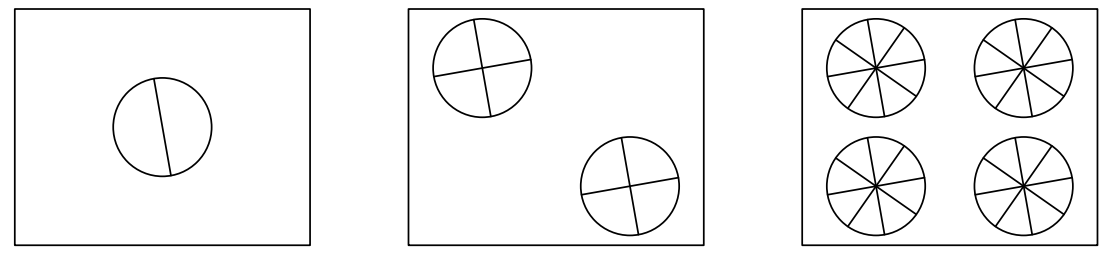

a) How much pizza will every child eat on each table?

b) In which table would you like to sit in order to eat more pizza?

Table 2

\begin{tabular}{|l|l|}
\hline \multicolumn{2}{|l|}{ utterances } \\
\hline 1 & E: (She is reading the problem). Well... \\
3 & A: $1 / 2$. \\
& E: (disturbed, she is addressing to the teacher) Apostolos is \\
& solving the problem alone. \\
& (Teacher: If there is a problem, you have to discuss it.) \\
4 & E: Well, the first is $1 / 2$, do you agree? In the first case, but why? \\
5 & A: The second one is $1 / 4$, it is obvious. \\
6 & E: Here $1 / 8$, ok? \\
7 & A: Ok. \\
8 & E: On which table would you like to sit in order to eat more \\
& pizza?
\end{tabular}




\begin{tabular}{|c|c|}
\hline 9 & A: We didn't do it right. \\
\hline 10 & E: Why? \\
\hline 11 & A: Here (he shows the $3^{\text {rd }}$ table) they will not eat $1 / 8$. \\
\hline 12 & E: It is. $\ldots 8$ plus $8 \ldots 16$ plus $16 \ldots 32.1 / 32$. \\
\hline 13 & $\begin{array}{l}\text { A: Look, we didn't think how many children are sitting on each } \\
\text { table. In the first table, } 2 \text { chil-dren are sitting, in the second } 4 \\
\text { and in the third } 8 \text {. So here (he shows the } 2^{\text {nd }} \text { table) it is } 4 / 8 \text {. } \\
\text { E: Right. }\end{array}$ \\
\hline 15 & A: And here (he shows the $3^{\text {rd }}$ table) it is $8 / 32$. \\
\hline
\end{tabular}

E: We had posed the target to discuss our ideas and then to write. Apostolos began to write alone without asking my opinion.

Researcher: How do you feel for this moment of your cooperation?

A: Not so well, I should ask Elsa.

E: Me too, I didn't like this. I had to remind Apostolos what we had agreed to do. I should not talk to the teacher.

Critical moments: The following dialogue from the third session is related with the way that the pupils' beliefs about their partner's ability influenced their inter-action in mathematics.

A: At the beginning we made an error. But later Elsa agreed with me and she didn't have a different idea.

Researcher: Do you think that this is negative for your cooperation?

A: Yes, because I do not want her to think that I am good and whatever I say is right.

E: No, it is not so. Because, sometimes I tell you my ideas, too.

It seems that Apostolos considered that his classmate did not offer ideas during their interaction, because she believed that he was better than she in mathematics, shifting the responsibility of their error to his partner.

In their fourth videotaped cooperation the following episode and the corresponding session with the researcher reveals the second critical moment of their meta-discursive reflection that is the absence of explanation for a mathematical decision. The given activity aimed at the recognition of the significance of the unit of reference in situations with fractions. The pupils could discuss about the sameness or the difference of the films concerning the number of photos (24 or 36 photos) and they could describe the different cases comparing the fractions. 
Episode 3: During an excursion, Helen used 2/4 of her film and Nikos used $2 / 6$ of his film. The children discussed about who took more photos. A. Who used more film and how much more? B. How much film was left over to every child?

Table 3

\begin{tabular}{|l|l|l|}
\hline \multicolumn{2}{|l|}{ utterances } & writings \\
\hline 1 & E: We have to find how much more. & \\
2 & A: How can we find it? & \\
3 & E: We will subtract $2 / 4$ from $2 / 6$ and we will & \\
& find it. & \\
4 & A: It is $2 / 2$, but it looks weird. & \\
5 & E: I thought something, the denominators are & \\
6 & not the same. & \\
& A: We can simplify them. $2 / 4$ can be $1 / 2$ and & \\
7 & $2 / 6$ can be $1 / 3$. & \\
8 & E: If we subtract them it is $1 / 1$. & {$[7]$ They wrote: } \\
9 & A: I don't did we find how much more? & $1 / 3-1 / 2=1 / 1$ \\
\hline
\end{tabular}

[1] E: Apostolos made an error in the subtraction, he subtracted $2 / 4$ from $2 / 6$ and he said it was $2 / 2$.

[2] A: But you accepted it, you didn't ask how I made it.

[3] E: I said that the denominators were not the same.

[4] A: Yes, but then we made the same subtraction again with a simplification and you accepted it.

[5] E: Yes, it seemed right to me.

[6] A: The first time we found $2 / 2$.

[7] E: And finally we found 1/1 again.

[8] A: It looked weird to me from the beginning.

[9] E: I was not sure at the end either. We didn't think why it could not be $1 / 1$.

Although both pupils tried to shift the responsibility for the error to their partner, they focused on the necessity of the existence of explanations for the solution of a mathematical problem (cf. ut. 2, 9). 
In this pair, the pupils' beliefs about cooperation and the partner's ability in mathematics played a significant role for the development of their interaction. As every pair in this class was obliged to design and present a drama, when Apostolos and Elsa discussed how to select the roles they would like to play, they proposed a scenario about two children, one of whom wanted to cooperate in mathematics and the other wanted to work alone. Apostolos would like to be the child that did not want to cooperate because: "The child who wants to work alone is good at mathematics". Elsa told him that "the other child can also be good at mathematics, but he likes to cooperate". Apostolos and Elsa represented two pupils who should cooperate in a mathematics class. Their drama text was the following:

E: 5 children want to share fairly 4 chocolates. How much chocolate will every child get?

A: Mister, I found it. (He represents that he is addressing to the teacher.)

E: Do you want to tell me your thinking and I tell you mine?

A: No, I don't want.

E: You don't want to discuss it and to solve it together?

A: No, I don't want at all.

E: Please, do it for my sake. It is better in this way, you will see it.

A: No and that's that.

Self-regulation: The targets set by the pupils at this level were related to the actions that they had to do in order to understand their partner's way of thinking.

E: We have to express our ideas and ask each other why it is so.

A: Yes, we must not write quickly. We have to ask each other how he found something.

\section{c) Focusing on mutual responsibility}

At the third level, the pupils began to reflect on their own responsibility about the development of their interaction. They assessed their cooperation according to their own efforts to explain their way of thinking to their partner in order to make a com-mon mathematical decision. The critical moments of their reflection were related to the fulfillment of their obligation to handle their different ideas by respecting their interlocutor's way of thinking. The self-regulation concerned their own personal ac-tions that are the actions that a pupil had to do in relation to his/her interlocutor in order to improve their interaction. This fact revealed the 


$$
\text { "chaviaris" — 2007/8/10 — 11:57 — page } 161 \text { — \#15 }
$$

mutual responsibility that the pupils began to develop in order to find common solutions in mathematics.

In the second drama Apostolos and Elsa decided to announce to their classmates their experience from their discussion about the interlocutors' responsibility for a mathematical error. The pupils chose to represent the discussion between two children in two scenes. At the first scene the two characters are speaking at the phone and at the second scene they are in the class checking their solution at the blackboard.

$1^{\text {th }}$ scene

[1] A: Hello, how are you;

[2] E: Fine, I do my mathematics.

[3] A: That's why I am speaking to you, for the problem that we have tomorrow.

[4] E: The problem about the pizzas.

[5] A: I think that in the first table they will eat $1 / 2$.

[6] E: Yes.

[7] A: In the second $2 / 4$.

[8] E: In the third $3 / 8$.

[9] A: Yes, ok, I 'll see you tomorrow.

[10] E: We didn't speak about the last... Oh! He hanged up!

$2^{\text {nd }}$ scene

[11] E: The results are correct.

[12] A: I think so.

[13] E: Let's see at the blackboard.

[14] A: Oh! (with surprise)

[15] E: What happened? Everything wrong!

[16] A: Everything. (disappointed)

[17] E: Why is it $1 / 4$, how did you find it?

[18] A: We had to discuss about it yesterday, when we spoke at the phone.

[19] A, E: Now, it's late. 


$$
\text { "chaviaris" — 2007/8/10 — 11:57 — page } 162 \text { — \#16 }
$$

After the presentation of the above role-play, the following discussion, that took place among all the pupils in the classroom, gave to Apostolos and Elsa the opportunity to express what they considered significant moments in their cooperation as well as to discuss about their own feelings.

[1] R: Do you want to talk to us about your roles?

[2] E: We would like to show you what happened to us when one of us spoke, the other agreed without either of us thinking whether it was right and we got it all wrong.

[3] A: We would like to show you that if you don't ask your classmate why what he says is so, if you don't understand it well enough, you should not accept it because both of you might make a mistake. What we mean to say is that it isn't possible for one pupil to say something and the other to write it. You should ask how he found it, why it is $1 / 2$. We were both led to making mistakes.

[4] Pupil 1: I like that, because I agree with what they said.

[5] Pupil 2: It's not only how he solved it, it could actually be wrong.

[6] A: Yes, but if you don't ask and you are too confident, you will not find the error.

[7] Pupil 3: I agree with Apostolos, because in this way you can think about what the other said.

At the end of the program, Apostolos and Elsa developed productive cooperation as, most of the time, each interlocutor challenged the other's participation (cf. interactivity flowchart 2, appendix). Most of their utterances were addressed to their interlocutor and they had mostly the form of questions (request for approval of a suggested mathematical action, request for explanation).

The following episode, during their last video-taped cooperation is representative.

Episode 4: Apostolos and Elsa were engaged with the following activity:

2 children share fairly $5 / 6$ of a pizza. How much pizza do every child get? 4 children share fairly $2 / 3$ of a pizza. How much pizza do every child get? 
Table 4

\begin{tabular}{|c|c|c|}
\hline \multicolumn{2}{|c|}{ utterances } & writings \\
\hline 1 & $\mathrm{E}$ : (She is reading the problem.) & \\
\hline $2 \mathrm{a}$ & A: 2 children, $5 / 6$ & \\
\hline $2 b$ & We can multiply 2 by $5 / 6$. & \\
\hline 3 & E: Yes. & \\
\hline 4 & A: Will we do it? & \\
\hline 5 & $\begin{array}{l}\text { E: Just a moment, every child does not take } \\
5 / 6 \text {, but they share } 5 / 6 \text {. }\end{array}$ & \\
\hline $6 \mathrm{a}$ & A: Ah, yes! & \\
\hline $6 b$ & $\begin{array}{l}\text { There are } 5 \text { pieces. Everyone will get } 2 \text { pieces } \\
\text { and it left over } 1 \text {. Right? }\end{array}$ & \\
\hline 7 & E: Yes. & [10] They are \\
\hline 8 & A: This one, don't we share it in two? & trying to draw \\
\hline 9 & E: Yes. & $5 / 6$ in a circle. \\
\hline 10 & A: Do you want to make a drawing? & \\
\hline 11 & $\mathrm{E}:$ It is better. & [17] They are \\
\hline 12 & A: I can't draw it in 6 pieces. & writing 10/12. \\
\hline 13 & $\mathrm{E}$ : It is difficult for me too. & \\
\hline 14 & A: If we use operations? & \\
\hline 15 & E: Let's try. & $5 / 12$ \\
\hline 16 & A: $5 / 6$ is $10 / 12$ that it can be shared by 2 . & \\
\hline 17 & E: Let's share it. & [23] She is \\
\hline 18 & A: 5/12 everyone. & writing \\
\hline 19 & $\begin{array}{l}\text { E: The second one. } 4 \text { children share fairly } 2 / 3 \\
\text { of a pizza. }\end{array}$ & $2 / 3=4 / 6$ \\
\hline 20 & A: Now, how can we share $2 / 3$ in $4 ?$ & \\
\hline 21 & $\mathrm{E}: 2 / 3$ is $4 / 6$ & \\
\hline 22 & A: $4 / 6 \ldots$ & $1 / 61 / 61 / 61 / 6$ \\
\hline 23 & $\mathrm{E}$ : It is $1 / 6,1 / 6$ and $1 / 6$ and $1 / 6$. & \\
\hline
\end{tabular}

At the end of the program, the pupils' beliefs about cooperation in mathematics had begun to change. Apostolos expressed the desire to cooperate with his classmates in mathematics, because "you can learn better, when you cooperate". However, he said that the partner in a pair influences the development of the cooperation by declaring that: "It depends on who is your partner. For example, if I cooperate with Paul who is very good in mathematics, he will talk and I will do nothing. But with Elsa, I can cooperate and I learn better". Elsa also declared that she would like to cooperate with her classmates in mathematics, because "It 


$$
\text { "chaviaris" — 2007/8/10 — 11:57 — page } 164 \text { — \#18 }
$$

is better to solve the problems together. You can hear different ideas and finally you find a good solution".

Although we could mention that at the end of the program the two pupils had made progress in solving problems with fractions, as both they had more flexibility concerning the strategies used (algebraic or based on visual models), we cannot argue that this progress is exclusively a result of the development of their metadiscursive reflection, as this pair participated in the whole class discussions, too. However, we can argue that through the improvement of their metacognition both pupils changed their mathematical behavior, i.e. they offered a proposal, they assessed other's argument, they explained the way of their mathematical thinking and they reflected on their errors.

\section{Conclusions}

The results of this study showed that the pupils were able to reflect on their own socio-mathematical behavior as they interacted in pairs and to participate actively in its reform, even though this was the first time of cooperation in mathematics in their school life. The two alternative environments (pupils' observations and discussions on their videotaped cooperation and pupils' participation in playing and acting in a drama) allowed the pupils to become aware of multiple aspects of their mathematical activity.

More specifically, in the first environment, the pupils had the opportunity to reflect on their own beliefs and practices about cooperation in mathematics, on the consequences of their actions as they tried to interact with their classmates and on the necessity of making changes in the manner of their interaction. Initially, the pupils reflected on their interactions according to the achievement of their own personal goals. Furthermore, their effort to communicate was experienced as an obstacle to their personal mathematical activity. Then, they commented on their partners' responsibility for the difficulties that they experienced in producing a common solution to a mathematical problem. Finally, they managed to reflect on the necessity of respecting and understanding their interlocutor's way of thinking as well as on their mutual responsibility for their socio-mathematical actions.

The second environment allowed them to reflect on their meta-discursive experiences focusing mostly on the emotional aspects of their interaction that is to understand the feelings of the other member by transferring them into roles. Moreover, this environment operated like a bridge among all the pairs' experiences 


$$
\text { "chaviaris" — 2007/8/10 — 11:57 — page } 165 \text { — \#19 }
$$

of this class allowing pupils to discuss the critical moments of their interactions [38].

However, as this research is a laboratory one, more evidence from the incorporation of these environments in the teaching practice of mathematics in different cultural classroom settings is necessary. Towards a direction that promotes pupil's learning autonomy and a deeper understanding of the reforming of classroom reality, the extension of this research can allow a deeper understanding of pupils' development of meta-discursive reflection on their socio-mathematical interaction and can lead to a better educational design for the teaching of mathematics.

\section{Acknowledgements}

The authors would like to thank Barry Zimmerman and the anonymous reviewers for their comments and valuable suggestions for revising this paper.

\section{Remarks}

The utterances of interlocutors are characterized as reactions to a targetphrase or proactions demanding a response. Their analysis allows the existence of distinct types of interaction among the members of the group. For example, such types of interaction are:

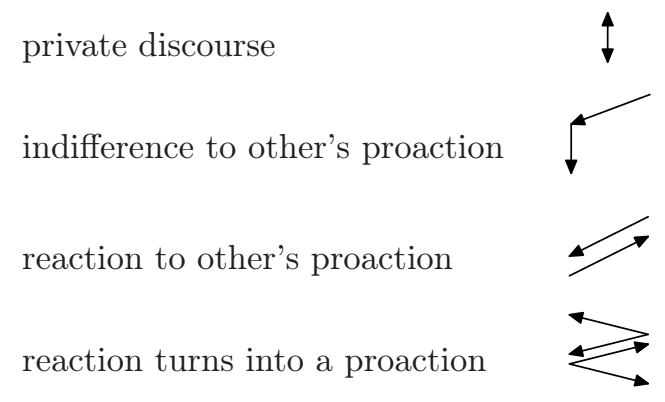




\section{Appendix}

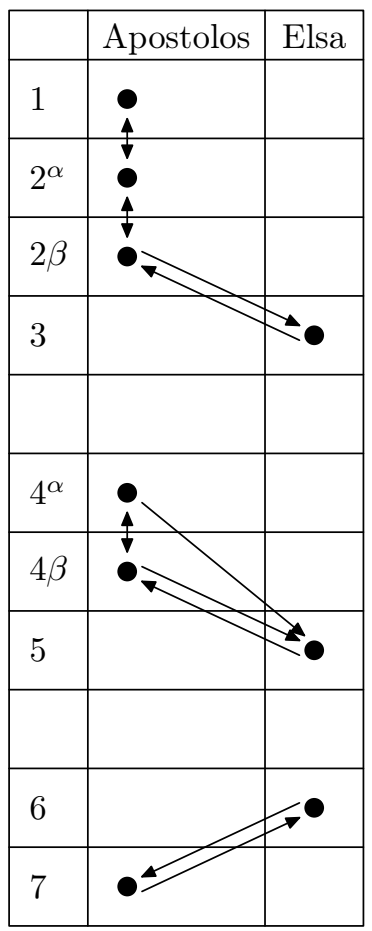

Interactivity flowchart 1
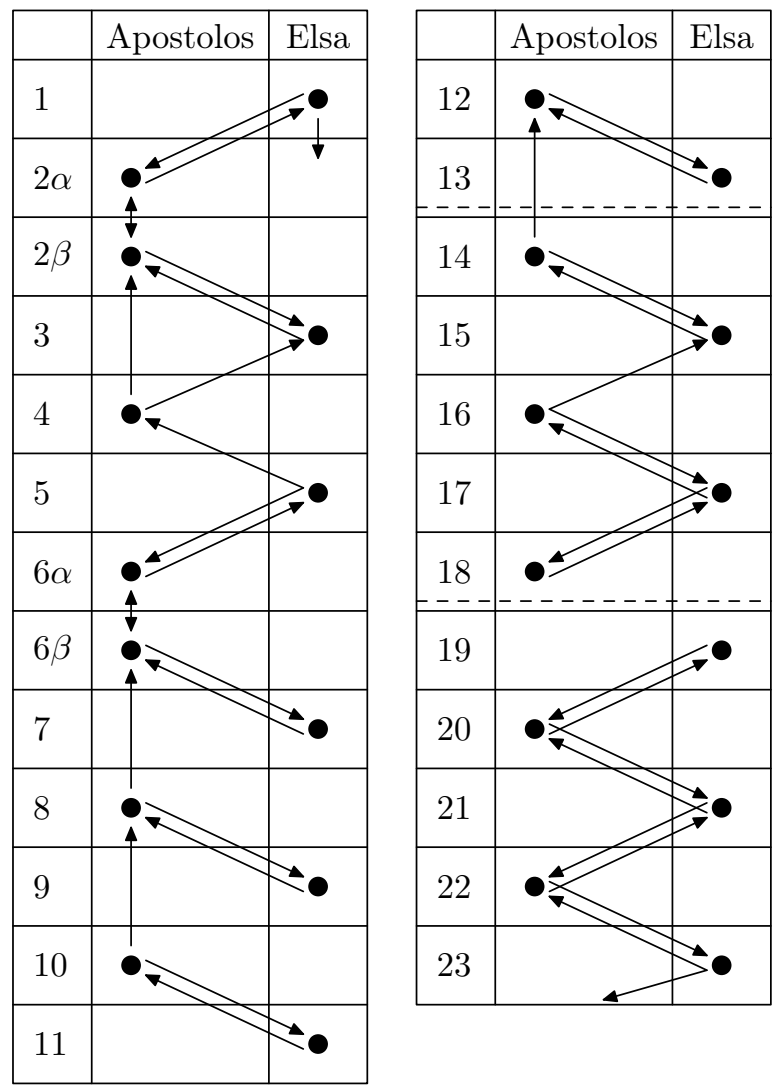

Interactivity flowchart 2

\section{References}

[1] B. Van Oers, Educational forms of initiation in mathematical culture, Educational Studies in Mathematics 46 (2001), 59-85.

[2] P. Cobb and H. Bauersfeld, Introduction: The coordination of psychological and sociological perspectives in Mathematics Education, in: The emergence of mathematical meaning: Interaction in Classroom Cultures, (P. Cobb and H. Bauersfeld, eds.), Lawrence Erlbaum Associates, Hillsdale, NJ, 1995, 1-16. 


$$
\text { "chaviaris" — 2007/8/10 — 11:57 — page } 167 \text { — \#21 }
$$

[3] S. Lerman, Cultural, Discursive Psychology: A Sociocultural Approach to Studying the Teaching and Learning of Mathematics, Educational Studies in Mathematics 46 (2001), 87-113.

[4] P. Cobb, T. Wood and E. Yackel, A constructivist approach to second grade mathematics, in: Radical Constructivism in Mathematics Education, (E. von Glasersfeld, ed.), Kluwer Academic Publishers, 1991, 157-176.

[5] K. McClain and P. Cobb, 236-266, Journal for Research in Mathematics Education 32, no. 3 (2001).

[6] R. Dekker and M. Elshout-Mohr, Teacher interventions aimed at mathematical level raising during collaborative learning, Educational Studies in Mathematics $\mathbf{5 6}$ (2004), 39-65.

[7] M. Veenman, B. Van Hout-Wolters and P. Afflerbach, Metacognition and Learning: conceptual and methodological considerations, Metacognition and Learning 1 (2006), 3-14.

[8] R. Hershkowitz and B. Schwarz, The Emergent Perspective in Rich Learning Environments: Some Roles of Tools and Activities in the Construction of Sociomathematical Norms, Educational Studies in Mathematics 39 (1999), 149-166.

[9] G. Brousseau, Le contrat didactique: le milieu, Recherches en Didactique des Mathématiques 9, no. 3 (1988), 309-336.

[10] E. Yackel and P. Cobb, Sociomathematical norms, argumentation and autonomy in mathematics, Journal for Research in Mathematics Education 27 (1996), 458-477.

[11] J. Voigt, Thematic Patterns of Interaction and Sociomathematical Norms, in: The emergence of mathematical meaning: Interaction in Classroom Cultures, (P. Cobb and H. Bauersfeld eds, eds.), Lawrence Erlbaum Associates, 1995, 163-201.

[12] A. Sfard, There is more to discourse than meets the ears: Looking at thinking as communicating to learn more about mathematical learning, Educational Studies in Mathematics 46, no. 1 (2001), 13-57.

[13] E. Yackel, C. Rasmusen and K. King, Social and sociomathematical norms in an advanced undergraduate mathematics course, Journal of Mathematical Behavior 19 (2000), 275-287.

[14] J. Moschkovich, What count as mathematical discourse?, Proceedings of the $2^{\text {rth }}$ Conference of the International Group for the Psychology of Mathematics Education 3, Honolulu, USA (2003), 325-331.

[15] B. J. Zimmerman, Self-regulation involves more than metacognition: A social cognitive perspective, Educational Psychologist 30 (1995), 217-221.

[16] A. J. Edwards, Learning Mathematics Collaboratively-Learning the Skills, Proceedings of $26^{\text {th }}$ Conference of the International Group for the Psychology of Mathematics Education 2, Norwich, UK (2002), 313-320.

[17] T. Good, C. Mulryan and M. McCaslin, Grouping for instruction in Mathematics: A call for programmatic research on small-group processes, in: Handbook of Research on Mathematics Teaching and Learning, (D. A. Grows, ed.), MacMillan, NY, 1992, 165-196. 
[18] C. Kieran, The mathematical Discourse of 13-Year-Old Partnered Problem Solving and its Relation to the Mathematics that Emerges, Educational Studies in Mathematics 46 (2001), 187-228.

[19] N. M. Webb, Peer interaction and learning in small groups, International Journal of Educational Research 13 (1989), 21-39.

[20] M. Goos, P. Galbraith and P. Renshaw, Socially mediated metacognition: Creating collaborative zones of proximal development in small group problem solving, Educational Studies in Mathematics 49 (2002), 193-223.

[21] B. Kramarski, Z. R. Mevarech and M. Arami, The effects of metacognitive instruction on solving mathematical authentic tasks, Educational Studies in Mathematics 49 (2002), 225-250.

[22] Z. R. Mevarech and B. Kramarski, IMPROVE: A multidimensional method for teaching mathematics in heterogeneous classrooms, American Educational Research Journal 34, no. 2 (1997), 199-224.

[23] S. Pape, C. Bell and I. Yetkin, Developing mathematical thinking and self-regulated learning: A teaching experiment in a seventh-grade mathematics classroom, Educational Studies in Mathematics 53 (2003), 179-202.

[24] A. H. Schoenfeld, Learning to think mathematically: problem solving, metacognition, and sense making in mathematics, in: Handbook of Research on Mathematics Teaching and Learning, (D. A. Grows, ed.), MacMillan, NY, 1992, 165-197.

[25] F. Furinghetti, F. Olivero and D. Paola, Watching video-recorded sessions as a support in the construction of a shared classroom culture, Proceedings of CIEAEM 51, Chichester, England (2000), 369-373.

[26] D. Wagner, Pupils and teachers listening to themselves: Language awareness in the mathematics classroom, Proceedings of the $2^{\text {rth }}$ Conference of the International Group for the Psychology of Mathematics Education 4, Honolulu, USA (2003), 355-362.

[27] A. Duatepe and B. Ubuz, Drama based instruction and geometry, 2002, http//www.icme-organisers.dk/tsg14/TSG14-12.pdf.

[28] C. Andersen, Thinking as and thinking about: Cognition and metacognition in drama in education, in: Playing betwixt and between: The IDEA dialogues 2001, (B. Rasmussen and A. L. Ostern, eds.), Landslaget, Drama i Skolen, Oslo, 2002, 265-270.

[29] G. Bolton and D. Heathcote, So you want to use role play? A new approach in how to plan, Treantham Books, London, 1999.

[30] J. L. Jensen and R. Rodgers, Cumulating the intellectual gold of case study research, Public Administration Review 61, no. 2 (2001), 236-246.

[31] S. Kemmis, Action research and social movement: A challenge for policy research, Education Policy Analysis Archives 1 (1993), http://epaa.asu/epaa/v1n1.html.

[32] T. E. Kieren, Rational and fractional numbers as mathematical and personal knowledge: Implications for curriculum and instruction, in: Analysis of arithmetic for mathematics teaching, (G. Leinhardt, R. Putnam and R. Hattrup, eds.), Lawrence Erlbaum Associates, Hillsdale, NJ, 1992, 323-372. 
[33] N. K. Mack, Learning rational numbers with understanding: The case of informal knowledge, in: Rational numbers: An integration of Research, (T. P. Carpenter, E. Fenemma and T. Romberg, eds.), Lawrence Erlbaum Associates, Hillsdale, NJ, 1993, 85-106.

[34] S. P. Marshall, Assessment of rational number understanding: A schema- based approach, in: Rational numbers: An integration of Research, (T. P. Carpenter, E. Fenemma and T. Romberg, eds.), Lawrence Erlbaum Associates, Hillsdale, NJ, 1993, 261-288.

[35] L. Streefland, Fractions in realistic mathematics education. A paradigm of developmental research, Kluwer Academic Publishers, Dordrecht, 1991.

[36] A. Sfard and C. Kieran, Cognition as communication, Rethinking learning by talking through multi-faceted analysis of pupils' mathematical interactions, Mind, Culture and Activity 8, no. 1 (2001), 42-76.

[37] F. Erickson, Qualitative methods in research on teaching, in: Handbook of research on teaching, $3^{\text {rd }}$ ed., (M. C. Wittrock, ed.), Macmillan, New York, 1986, 119-161.

[38] P. Chaviaris and F. Kalavassis, Role playing: an environment for the development of pupils' metadiscursive reflection in mathematics, Proceedings of CIEAEM 58 Congress, Srni, Czech Republic (2006), in press.

PETROS CHAVIARIS

PANAGI BENAKI 6

11471 ATHENS

GREECE

PHONE: 210-6452531

E-mail: chaviaris@rhodes.aegean.gr

(Received January, 2007) 